\title{
Chlorin e6 Prevents ADP-Induced Platelet Aggregation by Decreasing PI3K-Akt Phosphorylation and Promoting cAMP Production
}

\author{
Ji Young Park, ${ }^{1}$ Hyun Dong Ji, ${ }^{1}$ Bo Ra Jeon, ${ }^{1}$ Eun Ju Im, ${ }^{1}$ Young Min Son, \\ Joo Young Lee, ${ }^{1}$ Dong-Ha Lee, ${ }^{2}$ Young-Chul Lee, ${ }^{3}$ Eujin Hyun, ${ }^{3}$ Qi Jia, ${ }^{3}$ Mei Hong, ${ }^{3}$ \\ Hwa-Jin Park, ${ }^{2}$ and Man Hee Rhee ${ }^{1}$ \\ ${ }^{1}$ Laboratory of Veterinary Physiology and Cell Signaling, College of Veterinary Medicine, Kyungpook National University, \\ Daegu 702-701, Republic of Korea \\ ${ }^{2}$ Department of Biomedical Laboratory Science, College of Biomedical Science and Engineering and Regional Research Center, \\ Inje University, Gimhae 621-749, Republic of Korea \\ ${ }^{3}$ Unigen Inc., Cheonan, Chungnam 330-863, Republic of Korea
}

Correspondence should be addressed to Man Hee Rhee; rheemh@knu.ac.kr

Received 5 March 2013; Revised 19 June 2013; Accepted 19 June 2013

Academic Editor: Raffaele Capasso

Copyright (C) 2013 Ji Young Park et al. This is an open access article distributed under the Creative Commons Attribution License, which permits unrestricted use, distribution, and reproduction in any medium, provided the original work is properly cited.

\begin{abstract}
A number of reagents that prevent thrombosis have been developed but were found to have serious side effects. Therefore, we sought to identify complementary and alternative medicinal materials that are safe and have long-term efficacy. In the present studies, we have assessed the ability of chlorine e6 (CE6) to inhibit ADP-induced aggregation of rat platelets and elucidated the underlying mechanism. CE6 inhibited platelet aggregation induced by $10 \mu \mathrm{M}$ ADP in a concentration-dependent manner and decreased intracellular calcium mobilization and granule secretion (i.e., ATP and serotonin release). Western blotting revealed that CE6 strongly inhibited the phosphorylations of PI3K, Akt, c-Jun N-terminal kinase (JNK), and different mitogen-activated protein kinases (MAPKs) including extracellular signal-regulated kinase 1/2 (ERK1/2) as well as p38-MAPK. Our study also demonstrated that CE6 significantly elevated intracellular cAMP levels and decreased thromboxane $A_{2}$ formation in a concentration-dependent manner. Furthermore, we determined that CE6 initiated the activation of PKA, an effector of cAMP. Taken together, our findings indicate that CE6 may inhibit ADP-induced platelet activation by elevating cAMP levels and suppressing PI3K/Akt activity. Finally, these results suggest that CE6 could be developed as therapeutic agent that helps prevent thrombosis and ischemia.
\end{abstract}

\section{Introduction}

Vascular structure integrity is essential for the maintenance of cardiovascular function. Exposure to an injured vascular wall triggers the activation of platelets to promote the recovery of blood vessel integrity. However, aberrant platelet activation may result in thrombosis that could lead to the development of serious vascular diseases such as cerebral stroke and myocardial infarction.

Platelet agonists (e.g., ADP, thrombin, thromboxane $\mathrm{A}_{2}$ $\left(\mathrm{TXA}_{2}\right)$, and epinephrine) activate platelets via $\mathrm{G}$ proteincoupled receptor (GPCR) pathways $[1,2]$, and the activations of distinct $G$ proteins are integrated by interacting downstream molecules [3,4]. Thus, once a specific GPCR is activated by an agonist, other GPCRs are eventually activated by recruited GPCR ligands and form a positive feedback loop which greatly amplifies activation signals $[1,5]$. ADP and $\mathrm{TXA}_{2}$, two factors secreted during platelet activation, serve as both mediators and agonists. On the other hand, cyclic adenosine monophosphate (cAMP) and nitric oxide (NO), an endogenous gaseous molecule, have the opposite effects on platelet activation $[2,6,7]$. Adenylyl cyclase (AC) catalyzes the conversion of $5^{\prime}$-ATP into CAMP whereas phosphodiesterase (PDE) hydrolyzes cAMP. Intracellular cAMP levels are thus tightly regulated by AC and PDE [8]. 
A number of events involved in platelet activation are largely dependent on intracellular calcium levels $\left(\left[\mathrm{Ca}^{2+}\right]_{i}\right)$ [9], and elevation of $\left[\mathrm{Ca}^{2+}\right]_{i}$ is considered to be a prerequisite for platelet aggregation. The final common event of platelet aggregation is the binding of fibrinogen to integrin $\alpha_{\mathrm{IIb}} \beta_{3}$. The activation of integrin $\alpha_{\mathrm{IIb}} \beta_{3}$ mediates outside-in signaling that stimulates tyrosine phosphorylations to complete the process of platelet aggregation [10]. As such, platelet agonists, such as ADP and collagen, increase the affinity of $\alpha_{\mathrm{IIb}} \beta_{3}$ for fibrinogen that forms crosslinks between platelets [11].

Platelet activation triggers hemostasis, and the aberrant activation of platelets leads to thrombotic complications [12, 13]. Thrombosis is the formation of blood clots that can obstruct blood flow in a vessel. When thrombi form in a vessel, tissues can become hypoxic. This might lead to the development of serious thrombotic diseases including cerebral stroke and myocardial infarction $[14,15]$.

Over the last couple of decades, a number of antiplatelets drugs have been developed in response to the growing concern about cardiovascular diseases. However, these drugs were found to have undesirable side effects resulting from the direct inhibition of clotting factors. In our effort to find complementary and alternative compounds, we discovered CE6, a natural product that is made by chlorella species [16]. These algae have been used as traditional medicine in India [17] and Turkey [18] for treating inflammation-related diseases. Previous studies have also reported that CE6 has anticancer [19] and antiviral [20] effects. McMahon et al. [21] have examined the effects of CE6 on the changes of blood flow by measuring the diameters of cremaster arterioles ex vivo. Samal' et al. also described the antithrombotic effects of CE6 [22], but the underlying mechanism affecting the antiplatelet activities of this compound has not been elucidated. Therefore, we performed the current study to investigate the inhibitory effect of CE6 on ADP-induced platelet aggregation and the associated signaling mechanism governing this activity.

\section{Materials and Methods}

2.1. Materials. CE6 was obtained from Frontier Scientific, Inc. (Figure 1, Logan, UT, USA). Purity of the CE6 sample was more than $95 \%$. A $50 \mathrm{mM}$ stock solution of CE6 was prepared in DMSO and stored at $-20^{\circ} \mathrm{C}$ in the dark. The CE6 was diluted to the appropriate concentration immediately before all experiments were performed.

Fura-2/AM was obtained from Sigma Chemical Co. (St. Louis, MO, USA). ADP was procured from Chrono-log (Havertown, PA, USA). Antibodies against phospho-p44/42, p44/42, phospho-p38, p38, phospho-SAPK/JNK, phosphoPI3K (p85), phospho-Akt, and $\beta$-actin were acquired from Cell Signaling (Beverly, MA, USA). Antibody against the catalytic subunit of PKA (PKA $\alpha / \beta / \gamma$ cat) was from Santa Cruz (Delaware Avenue, CA, USA). ATP assay kits were purchased from Biomedical Research Service Center (Buffalo, NY, USA). A TXB ${ }_{2}$ enzyme immunoassay (EIA) kit was purchased from Enzo Life Sciences (Plymouth Meeting, PA, USA). A cAMP EIA kit was obtained from Cayman Chemical (Ann Arbor, MI, USA). Fibrinogen Alexa Fluor 488 conjugate

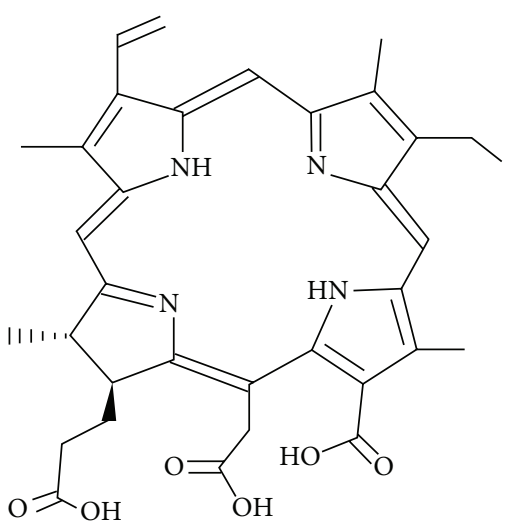

Figure 1: The chemical structure of CE6.

was obtained from Molecular Probes (Eugene, OR, USA). All chemicals were of reagent grade.

2.2. Rat Platelet Preparation. Rat platelets were isolated and prepared as previously described [23]. Male Sprague Dawley rats $60 \mathrm{~d}$ old and weighing from 240 to $250 \mathrm{~g}$ were obtained from Orient Co. (Seoul, Republic of Korea). The animals were maintained in a standard laboratory animal facility with free access to food and water. Whole blood from the rats was collected using a $23 \mathrm{G}$ needle inserted into the abdominal aorta, and then transferred to a $15 \mathrm{~mL}$ test tube containing $1 \mathrm{~mL}$ of an acid/citrate/dextrose (ACD) solution ( $85 \mathrm{mM}$ trisodium citrate, $83 \mathrm{mM}$ dextrose, and $21 \mathrm{mM}$ citric acid) as an anticoagulant. The blood was centrifuged at $170 \times \mathrm{g}$ for $7 \mathrm{~min}$ to obtain platelet-rich plasma (PRP). In order to remove residual erythrocytes, the PRP samples were again centrifuged at $120 \times \mathrm{g}$ for $7 \mathrm{~min}$. To isolate the platelets and remove the ACD solution, the PRP was centrifuged twice at $350 \times \mathrm{g}$ for $10 \mathrm{~min}$ with a washing buffer. The concentration of platelets from the precipitate was adjusted to $3 \times 10^{8} / \mathrm{mL}$ with Tyrode buffer $\left(137 \mathrm{mM} \mathrm{NaCl}, 12 \mathrm{mM} \mathrm{NaHCO}_{3}, 5.5 \mathrm{mM}\right.$ glucose, $2 \mathrm{mM} \mathrm{KCl}, 1 \mathrm{mM} \mathrm{MgCl}_{2}$, and $0.3 \mathrm{mM} \mathrm{NaHPO}_{4}$, $\mathrm{pH}$ 7.4) for the aggregation assay. Platelet preparation was conducted at room temperature. Experimental procedures and protocols involving animals were reviewed and approved by the Ethics Committee of the College of Veterinary Medicine, Kyungpook National University (Daegu, Republic of Korea).

2.3. Platelet Aggregation Assay. Platelet aggregation was evaluated as previously described [24]. Aggregation was monitored by measuring light transmission with an aggregometer (Chrono-log, Havertown, PA, USA). The washed platelets $\left(3 \times 10^{8} / \mathrm{mL}\right)$ were preincubated at $37^{\circ} \mathrm{C}$ for 2 min with either CE6 or vehicle and then stimulated with $10 \mu \mathrm{M}$ ADP. The mixture was further incubated for $5 \mathrm{~min}$ with stirring. The vehicle concentration was less than $0.1 \%$ to minimize the effect of this reagent.

2.4. $\left[\mathrm{Ca}^{2+}\right]_{i}$ Measurement. The intracellular calcium ion concentration $\left(\left[\mathrm{Ca}^{2+}\right]_{i}\right)$ was measured with Fura-2/AM as 
previously described [25]. Briefly, the platelets were incubated with $5 \mu \mathrm{M}$ of Fura-2/AM for $30 \mathrm{~min}$ at $37^{\circ} \mathrm{C}$ and washed. The Fura-2-loaded platelets $\left(3 \times 10^{8} / \mathrm{mL}\right)$ were then pre-incubated with $\mathrm{CE} 6$ for $2 \mathrm{~min}$ at $37^{\circ} \mathrm{C}$ in the presence of $1 \mathrm{mM} \mathrm{CaCl}_{2}$, and subsequently stimulated with ADP for $5 \mathrm{~min}$. Fluorescent signals were recorded using a Hitachi F-2500 fluorescence spectrofluorometer (F-2500, Hitachi, Japan). Light emission was measured at $510 \mathrm{~nm}$, with simultaneous excitation at 340 and $380 \mathrm{~nm}$ that changed every $0.5 \mathrm{~s}$. Fura-2 fluorescence in the cytosol measured with the spectrofluorometer was calculated as previously described by Schaeffer and Blaustein [26] with the following formula: $\left[\mathrm{Ca}^{2+}\right]_{i} 224 \mathrm{nM} \times(F-$ $\left.F_{\text {min }}\right) /\left(F_{\max }-F\right)$, in which $224 \mathrm{nM}$ is the dissociation constant of the Fura-2- $\mathrm{Ca}^{2+}$ complex, and $F_{\min }$ and $F_{\max }$ represent the fluorescence intensity levels at very low and very high $\mathrm{Ca}^{2+}$ concentrations, respectively. In our experiment, $F_{\text {max }}$ was the intensity of the Fura-2-Ca ${ }^{2+}$ complex fluorescence at $510 \mathrm{~nm}$ after the platelet suspension containing $1 \mathrm{mM}$ of $\mathrm{CaCl}_{2}$ had been solubilized with Triton X-100 (0.1\%). $F_{\min }$ was the fluorescence intensity of the Fura-2- $\mathrm{Ca}^{2+}$ complex at $510 \mathrm{~nm}$, after the platelet suspension containing $20 \mathrm{mM}$ Tris/ $3 \mathrm{mM}$ of EGTA had been solubilized with Triton X$100(0.1 \%) . F$ represented the intensity of Fura-2 complex fluorescence at $510 \mathrm{~nm}$ after the platelet suspension which was stimulated with ADP with or without CE6 in the presence of $1 \mathrm{mM} \mathrm{CaCl}_{2}$.

2.5. ATP Release Assay. Washed platelets $\left(3 \times 10^{8} / \mathrm{mL}\right)$ were pre-incubated for $2 \mathrm{~min}$ at $37^{\circ} \mathrm{C}$ with various concentrations of CE6 and then stimulated with $10 \mu \mathrm{M}$ ADP. After the reaction was terminated, the cells were centrifuged and the supernatants were used for the assay. ATP release was measured in a luminometer (GloMax 20/20, Promega, Madison, USA) using an ATP assay kit (Biomedical Research Service Center, Buffalo, NY, USA) according to manufacturer's instructions.

2.6. Serotonin Release Assay. A platelet aggregation assay was carried out as described previously. After terminating the aggregation reaction, the mixture was immediately centrifuged at $12,000 \times \mathrm{g}$ for $5 \mathrm{~min}$ at $4^{\circ} \mathrm{C}$. The supernatant was collected and serotonin release was measured with a serotonin ELISA kit (Labor Diagnostika Nord GmbH \& Co, Nordhorn, Germany) according to the manufacturer's instructions.

2.7. Cyclooxygenase-1 (COX-1) Activity Assay. The washed platelets $\left(3 \times 10^{8} / \mathrm{mL}\right)$ with $1 \%$ protease inhibitor cocktail (Sigma Chemical Co., St. Louis, MO, USA) were sonicated 10 times at sensitivity $100 \%$ for $20 \mathrm{~s}$ on ice with a model HD2070 sonicator (Bandelin Electronic, Bandelin, Germany) to obtain platelet lysates. The homogenates were centrifuged at $12,000 \times \mathrm{g}$ for $15 \mathrm{~min}$ at $4^{\circ} \mathrm{C}$ to remove cell debris. The supernatant was used to measure COX-1 activity. The platelet lysates were pre-incubated with $330 \mathrm{nM}$ SC-560, a selective COX-1 inhibitor, and with or without various concentrations of CE6 at $37^{\circ} \mathrm{C}$ for $30 \mathrm{~min}$. COX-1 activity of the treated platelet lysates was then measured with a COX-1 fluorescent assay kit (Cayman Chemical Co., Ann Arbor, MI, USA) according to the manufacturer's protocol.

2.8. Measurement of Thromboxane A Synthase (TXAS) Activity. The washed platelets $\left(3 \times 10^{8} / \mathrm{mL}\right)$ with $1 \%$ protease inhibitor cocktail (Sigma Chemical Co., St. Louis, MO, USA) were sonicated 10 times at sensitivity $100 \%$ for 20 s on ice with a model HD2070 sonicator (Bandelin Electronic, Bandelin, Germany) to obtain platelet lysates. Next, the homogenates were centrifuged at $12,000 \times \mathrm{g}$ for $15 \mathrm{~min}$ at $4^{\circ} \mathrm{C}$ to remove cell debris. TXAS activity of the supernatant was then measured. The platelet lysates were pre-incubated with $11 \mathrm{nM}$ ozagrel, a TXAS inhibitor, with or without various concentrations of CE6 at $37^{\circ} \mathrm{C}$ for $30 \mathrm{~min}$. The reaction was initiated by the addition of prostaglandin $\mathrm{H} 2\left(\mathrm{PGH}_{2}\right)$ and allowed to proceed for $1 \mathrm{~min}$ at $37^{\circ} \mathrm{C}$. The reaction was then terminated by the addition of $1 \mathrm{M}$ citric acid. After neutralization with $1 \mathrm{~N} \mathrm{NaOH}$, the concentration of thromboxane $\mathrm{B}_{2}\left(\mathrm{TXB}_{2}\right)$, a stable metabolite of $\mathrm{TXA}_{2}$, was determined with a $\mathrm{TXB}_{2}$ EIA kit (Cayman Chemical Co, Ann Arbor, MI, USA) according to the manufacturer's instructions.

2.9. Evaluation of $\mathrm{TX}_{2}$ Generation. Washed platelets $(3 \times$ $10^{8} / \mathrm{mL}$ ) were pre-incubated with or without CE6 for 2 min at $37^{\circ} \mathrm{C}$ in the presence of $1 \mathrm{mM} \mathrm{CaCl}_{2}$, and then stimulated with $10 \mu \mathrm{M}$ ADP for $5 \mathrm{~min}$. The reactions were terminated by adding ice-cold $2.5 \mathrm{mM}$ EDTA and $100 \mu \mathrm{M}$ indomethacin. After centrifugation at $12,000 \times \mathrm{g}$ for $3 \mathrm{~min}$ at $4^{\circ} \mathrm{C}$, the supernatant was collected and the concentration of $\mathrm{TXB}_{2}$ was measured using a $\mathrm{TXB}_{2}$ EIA kit according to the manufacturer's protocol.

2.10. Measurement of $c A M P$ Levels. Washed platelets $(3 \times$ $10^{8} / \mathrm{mL}$ ) were incubated at $37^{\circ} \mathrm{C}$ for $5 \mathrm{~min}$ with vehicle (DMSO), CE6 $(1,4$, and $8 \mu \mathrm{M})$, or forskolin $(1 \mu \mathrm{M})$ in either the presence or absence of $10 \mu \mathrm{M}$ ADP with stirring in an aggregometer (Chronolog, Havertown, PA, USA). Immediately after terminating the incubation, the mixture was boiled for $5 \mathrm{~min}$ and cooled to $4^{\circ} \mathrm{C}$. The samples were then centrifuged at $2,000 \times \mathrm{g}$ for $10 \mathrm{~min}$ at $4^{\circ} \mathrm{C}$. The concentration of cAMP in the supernatants was determined with a cAMP EIA kit according to the manufacturer's protocol.

2.11. Immunoblotting. Platelet suspensions $\left(3 \times 10^{8} / \mathrm{mL}\right)$ were pre-incubated with CE6 or vehicle $(0.1 \%(\mathrm{v} / \mathrm{v})$ DMSO) at $37^{\circ} \mathrm{C}$ for $2 \mathrm{~min}$. Platelet activation was induced by the addition of $10 \mu \mathrm{M}$ ADP and the reaction was allowed to proceed for $5 \mathrm{~min}$. After terminating the reaction, lysates were then prepared by solubilizing and centrifuging the platelets in sample buffer $(0.125 \mathrm{M}$ Tris- $\mathrm{HCl}, \mathrm{pH} 6.8 ; 2 \%$ SDS, $2 \% \beta$-mercaptoethanol, $20 \%$ glycerol, $0.02 \%$ bromophenol blue, $1 \mu \mathrm{g} / \mathrm{mL}$ phenylmethylsulfonyl fluoride (PMSF), $2 \mu \mathrm{g} / \mathrm{mL}$ aprotinin, $1 \mu \mathrm{g} / \mathrm{mL}$ leupeptin, and $1 \mu \mathrm{g} / \mathrm{mL}$ pepstatin A). Protein concentration was determined using a BCA assay (Pro-Measure; iNtRON Biotechnology, Seoul, Republic of Korea). Total cell proteins $(30 \mu \mathrm{g})$ from the platelet lysate were resolved by $10 \%$ SDS-PAGE and transferred to nitrocellulose membranes in transfer buffer $(25 \mathrm{mM}$ Tris, 


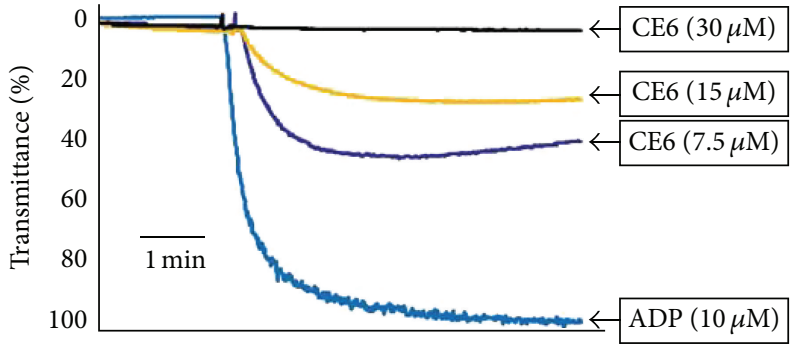

(a)

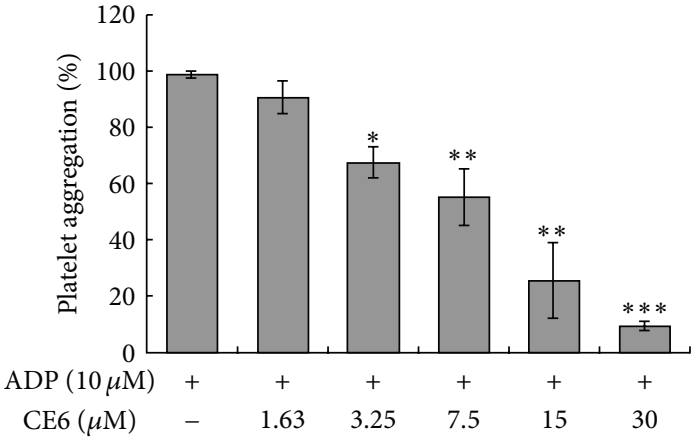

(b)

FIGURE 2: The inhibitory effect of CE6 on platelet aggregation induced by ADP. Platelets $\left(3 \times 10^{8} / \mathrm{mL}\right)$ were preincubated with or without CE6 $(1.63-30 \mathrm{M})$ in the presence of $1 \mathrm{mM} \mathrm{CaCl}_{2}$ for $2 \mathrm{~min}$ at $37^{\circ} \mathrm{C}$. The platelet aggregation was then induced by $10 \mu \mathrm{M}$ ADP and measured with a turbidimetric aggregometer. The aggregation reaction was terminated after $5 \mathrm{~min}$, and the percent aggregation rate was calculated. Each graph shows the mean \pm SEM of four independent experiments. ${ }^{*} P<0.05,{ }^{* *} P<0.01$, and ${ }^{* * *} P<0.001$ compared to the agonist control.

pH 8.5; $0.2 \mathrm{M}$ glycine; and 20\% methanol). The membranes were blocked in TBS-T containing 5\% nonfat dry milk and incubated with primary antibody diluted in a blocking solution. The blots were then incubated with horseradish peroxidase-conjugated secondary antibody. Antibody binding was visualized using enhanced chemiluminescence (iNtRON Biotechnology, Seoul, Republic of Korea).

2.12. Assessment of Fibrinogen Binding to Integrin $\alpha_{\mathrm{IIb}} \beta_{3}$. Fibrinogen Alexa Fluor 488 conjugate binding to washed platelets was quantified by flow cytometry. Briefly, washed platelets $\left(3 \times 10^{8} / \mathrm{mL}\right)$ were pre-incubated for $2 \mathrm{~min}$ with various concentrations of $\mathrm{CE} 6$ at room temperature in the presence of $0.1 \mathrm{mM} \mathrm{CaCl}_{2}$. The platelets were then stimulated with ADP for $5 \mathrm{~min}$, immediately incubated thereafter with fibrinogen Alexa Fluor $488(20 \mu \mathrm{g} / \mathrm{mL})$ for $5 \mathrm{~min}$, and finally fixed with $0.5 \%$ paraformaldehyde at $4^{\circ} \mathrm{C}$ for $30 \mathrm{~min}$. The platelets were pelleted by centrifugation at $2,000 \times \mathrm{g}$ at $4^{\circ} \mathrm{C}$ and resuspended in $500 \mu \mathrm{L}$ PBS. Since the activation of integrin $\alpha_{\mathrm{IIb}} \beta_{3}$ is largely dependent on the generation of $\mathrm{Ca}^{2+}$, nonspecific binding of fibrinogen to integrin $\alpha_{\mathrm{IIb}} \beta_{3}$ was measured by assessing fibrinogen binding in the presence of the calcium chelator EGTA $(1 \mathrm{mM})$. The fluorescence of each platelet sample was analyzed using a FACS Calibur cytometer (BD Biosciences, San Jose, CA, USA), and data were analyzed using CellQuest software (Becton Dickinson Immunocytometry Systems, San Jose, CA, USA).

2.13. Statistical Analysis. Data were analyzed with a one-way analysis of variance followed by a post hoc Dunnett's test in order to measure statistical significance of the differences observed (SAS Institute Inc., Cary, NC, USA). All data are presented as the mean \pm standard error of the mean (SEM). $P$ values of 0.05 or less were considered to be statistically significant.

\section{Results}

3.1. CE6 Inhibits ADP-Induced Platelet Aggregation. We first determined whether CE6 affected platelet aggregation

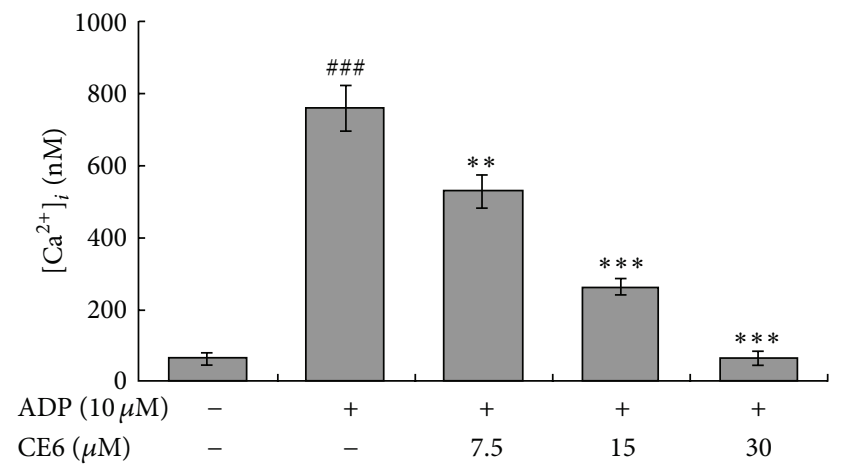

FIgure 3: The inhibitory effect of CE6 on $\left[\mathrm{Ca}^{2+}\right]_{i}$ increased by ADP. Washed platelets $\left(3 \times 10^{8} / \mathrm{mL}\right)$ were incubated with calcium fluorophore (5 M, Fura-2/AM) and stimulated with $10 \mu \mathrm{M}$ ADP. $\left[\mathrm{Ca}^{2+}\right]_{i}$ was then measured as described in Section 2. The results are presented as the mean \pm SEM of three independent experiments. ${ }^{* *} P<0.01$ and ${ }^{* * *} P<0.005$ compared to the agonist control. \#\#\# $P<0.001$ compared to the basal level.

induced by $10 \mu \mathrm{M}$ ADP. CE6 significantly inhibited ADPinduced platelet aggregation in a concentration-dependent manner with an $\mathrm{IC}_{50}$ of $12.53 \pm 2.79 \mu \mathrm{M}$ (Figure 2).

3.2. CE6 Prevents ADP-Induced $\left[\mathrm{Ca}^{2+}\right]_{i}$ Elevation. Since the mobilization of calcium is a crucial step for platelet activation and degranulation [27], we examined the effect of CE6 on the elevation of $\left[\mathrm{Ca}^{2+}\right]_{i}$ induced by ADP. As shown in Figure 3, $\operatorname{ADP}(10 \mu \mathrm{M})$ increased $\left[\mathrm{Ca}^{2+}\right]_{i}$ to $750 \mathrm{nM}$. This was markedly suppressed by CE6 in a concentration-dependent manner. Our results suggest that the inhibition of platelet aggregation by CE6 is potentially mediated by the regulation of $\left[\mathrm{Ca}^{2+}\right]_{i}$.

3.3. CE6 Inhibits ATP Release from ADP-Activated Platelets. Since the contents of dense granules are rapidly released as an early event of platelet activation [28], we measured ATP secretion induced by ADP as an index of dense granule 


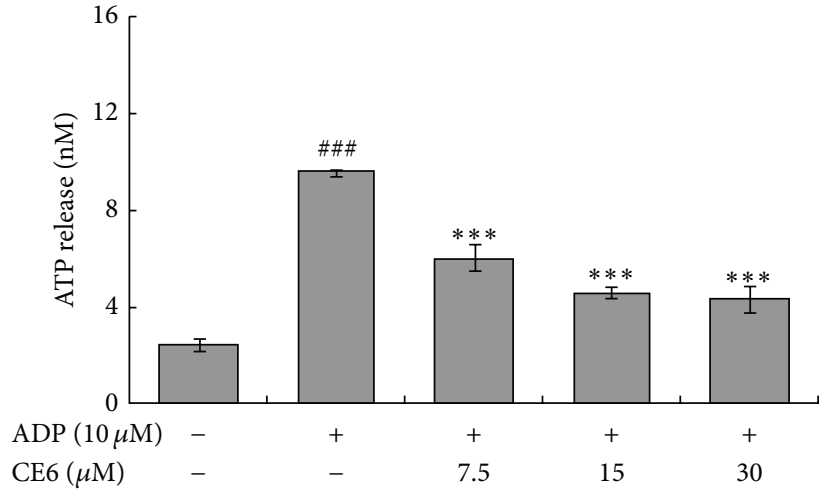

(a)

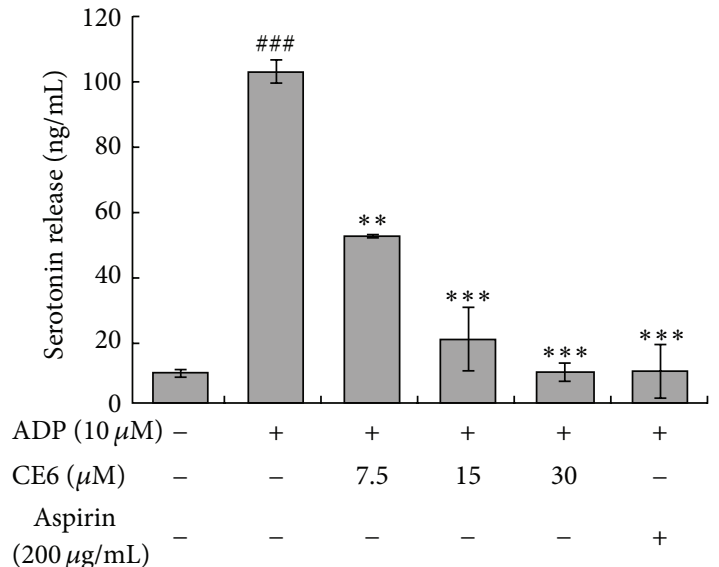

(b)

FIGURE 4: Effects of CE6 on granule secretion from the ADP-activated platelets. Washed platelets $\left(3 \times 10^{8} / \mathrm{mL}\right)$ were pre-incubated with CE6 at the indicated concentrations and stirred in an aggregometer for 2 min prior to stimulation with ADP for 5 min. The reaction was terminated, and an ATP release assay (a) and serotonin release assay (b) were performed. Bar graphs show the mean \pm SEM of at least four independent experiments. ${ }^{* *} P<0.01$ and ${ }^{* * *} P<0.001$ compared to the agonist control. ${ }^{\# \#} P<0.001$ compared to the basal level.

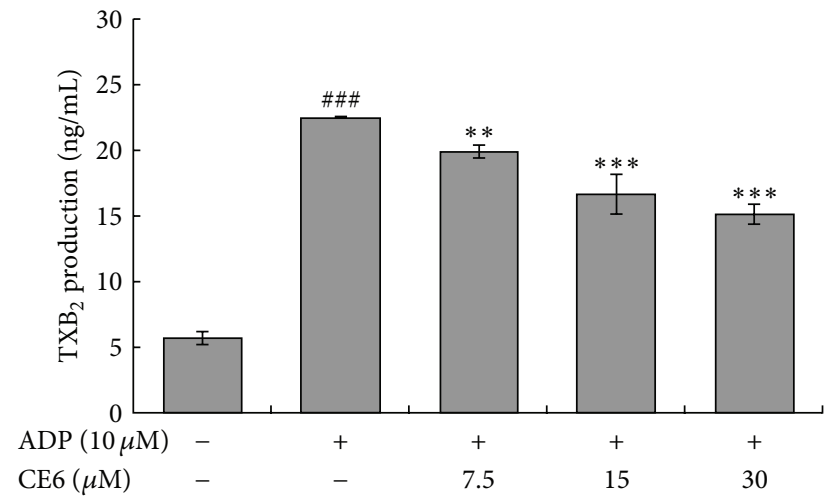

Figure 5: Effect of CE6 on ADP-induced $\mathrm{TXB}_{2}$ generation. Platelets $\left(3 \times 10^{8} / \mathrm{mL}\right)$ were pre-incubated with or without CE6 $(7.5-30 \mathrm{M})$ in the presence of $1 \mathrm{mM} \mathrm{CaCl}_{2}$ for $2 \mathrm{~min}$ at $37^{\circ} \mathrm{C}$. The platelets were then stimulated with $10 \mu \mathrm{M}$ ADP for $5 \mathrm{~min}$ at $37^{\circ} \mathrm{C}$. After terminating the aggregation reaction, the supernatant was collected and $\mathrm{TXB}_{2}$ production was measured using a $\mathrm{TXB}_{2}$ EIA kit according to the manufacturer's instructions. Bar graphs show the mean \pm SEM of three independent experiments performed. ${ }^{* *} P<0.01$ and ${ }^{* * *} P<$ 0.005 compared to the agonist control. ${ }^{\# \# \#} P<0.001$ compared to the basal level.

secretion. Compared to treatment with vehicle, CE6 significantly inhibited ATP release from ADP-stimulated platelets (Figure 4).

\subsection{CE6 Reduces Serotonin Release from ADP-Activated Plate-} lets. Serotonin (5-hydroxytryptamine) accumulates in platelet dense granules and is released during the initial stage of platelet activation with various ligands such as collagen, thrombin, and ADP $[29,30]$. As shown in Figure 5, CE6 significantly suppressed ADP-induced serotonin release from the rat platelets in a concentration-dependent manner. Taken

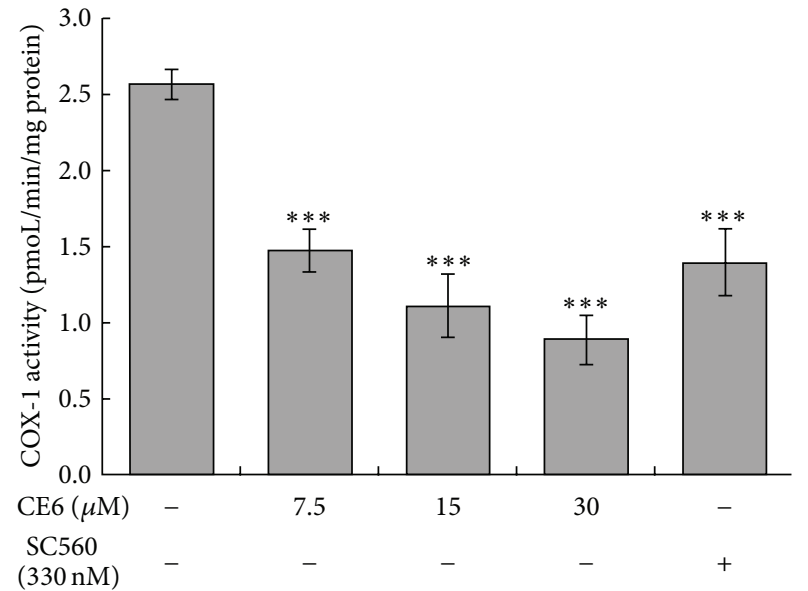

FIGURE 6: Effect of CE6 on COX-1 activity in the intact platelets. Platelets $\left(3 \times 10^{8} / \mathrm{mL}\right)$ with protease inhibitor cocktail were sonicated 10 times at sensitivity $100 \%$ for $20 \mathrm{~s}$ on ice with sonicator. The homogenates were centrifuged at $12,000 \times \mathrm{g}$ for $15 \mathrm{~min}$ at $4^{\circ} \mathrm{C}$ to remove cell debris. The supernatant was used to measure COX1 activity. The platelet lysates were pre-incubated with or without various concentrations of CE6 at $37^{\circ} \mathrm{C}$ for $30 \mathrm{~min}$. COX-1 activity of the treated platelet lysates was then measured with a COX-1 assay kit according to the manufacturer's protocol. Bar graphs show the mean \pm SEM of three independent experiments. ${ }^{* * *} P<0.005$ compared to the agonist control.

together, our findings showed that CE6 markedly inhibited degranulation during the early step of ADP-induced platelet activation.

3.5. CE6 Suppresses $T X A_{2}$ Production. $\mathrm{TXA}_{2}$, a lipid mediator, is a key element that amplifies activation signals. To examine the effects of CE6 on $\mathrm{TXA}_{2}$ production, we quantified 

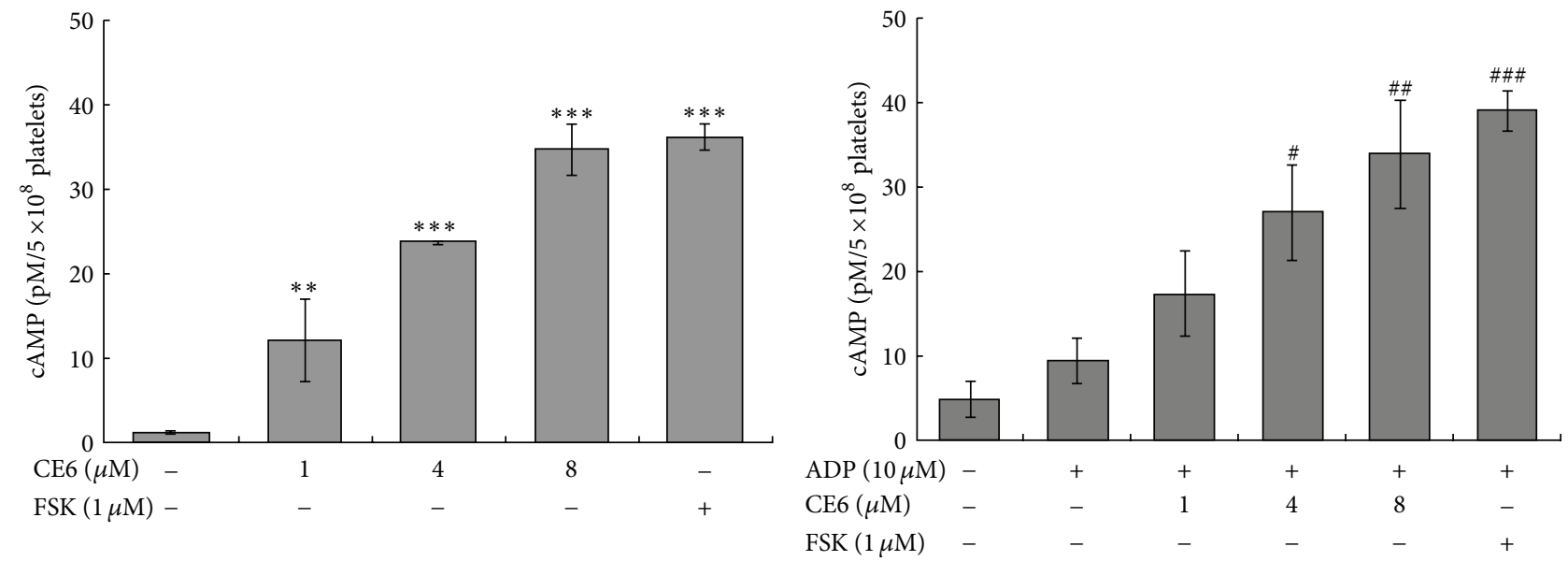

(a)

(b)

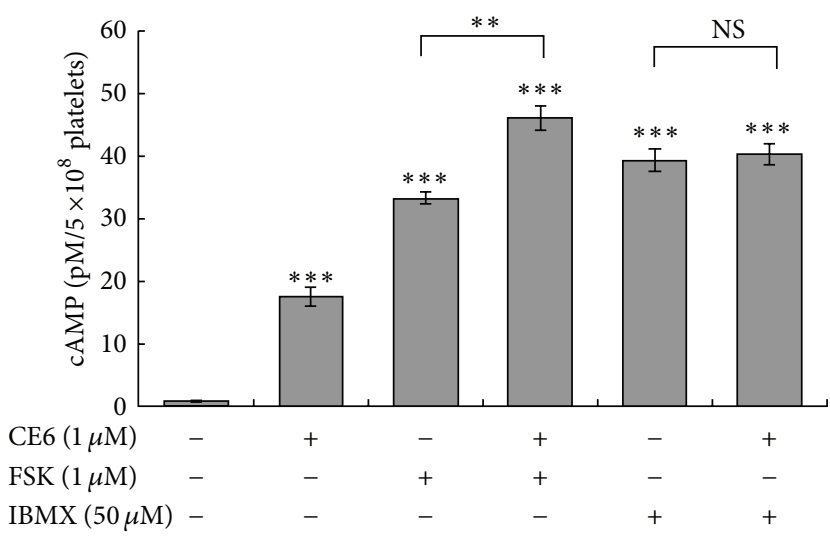

(c)

FIGURE 7: Effects of CE6 on intracellular cAMP concentrations. Washed platelets $\left(3 \times 10^{8} / \mathrm{mL}\right)$ were stirred with vehicle (DMSO) or CE6 (at the indicated concentrations), forskolin, or IBMX in an aggregometer and stimulated with $10 \mu \mathrm{M}$ ADP for 5 min. cAMP levels were then measured with an immunoassay as described in Section 2. CE6 significantly increased cAMP accumulation in a concentration-dependent manner (a). Co-incubation with CE6 and forskolin but not IBMX synergistically increased cAMP levels (b). The results are presented as the mean \pm SEM of at least three independent experiments. ${ }^{* *} P<0.01$, and ${ }^{* * *} P<0.005$ compared to the negative control. ${ }^{\#} P<0.05$, ${ }^{\# *} P<0.01$, and ${ }^{\# \# \# ~} P<0.001$ compared to the ADP-activated control. NS: not significant.

the levels of $\mathrm{TXB}_{2}$, a stable metabolite of TXA 2 in CE6-treated platelets. As presented in Figure 6, ADP greatly increased $\mathrm{TXB}_{2}$ generation five times more compared to the basal level. Production of this metabolite was gradually reduced by CE6.

3.6. CE6 Inhibits COX-1 Activity but Not TXAS Activity. $\mathrm{TXA}_{2}$, a powerful aggregating agent that acts as an autacoid, can be produced via sequential activation of COX-1 and TXAS. First, COX-1 catalyzes the conversion of arachidonic acid into $\mathrm{PGH}_{2}$, which is transformed into $\mathrm{TXA}_{2}$ with the aid of TXAS [23]. We determined whether CE6 modulated the activities of COX-1 and TXAS in unstimulated rat platelets. Surprisingly, CE6 inhibited COX-1 activity in a concentration-dependent manner compared to SC-560, a selective COX-1 inhibitor (Figure 6). However, CE6 did not affect TXAS activity (data not shown).
3.7. CE6 Increases cAMP Production in Resting and ADPActivated Platelets. As shown in Figure 7(a), preincubation with CE6 significantly increased the cAMP levels in intact platelets. At a concentration of $8 \mu \mathrm{M}$, CE6 increased cAMP concentrations to $95 \%$ of that observed in cells treated with forskolin. However, ADP has a little effect on cAMP production while CE6 augmented CAMP production in ADPactivated platelets with the similar extent in resting platelets (Figure 7(b)). Furthermore, coincubation with CE6 and $1 \mu \mathrm{M}$ forskolin, a direct AC activator, promoted the increase of cAMP levels induced by CE6 (Figure 7(c)). However, coincubation with CE6, 3-isobutyl-1-methylxanthine (IBMX), a broad-spectrum PDE inhibitor, had a little synergistic effect on cAMP production.

3.8. CE6 Inhibits the Phosphorylation of MAPKs, PI3K, and Akt and Increases Expression of the PKA Catalytic Subunit. In order to elucidate the mechanism underlying 

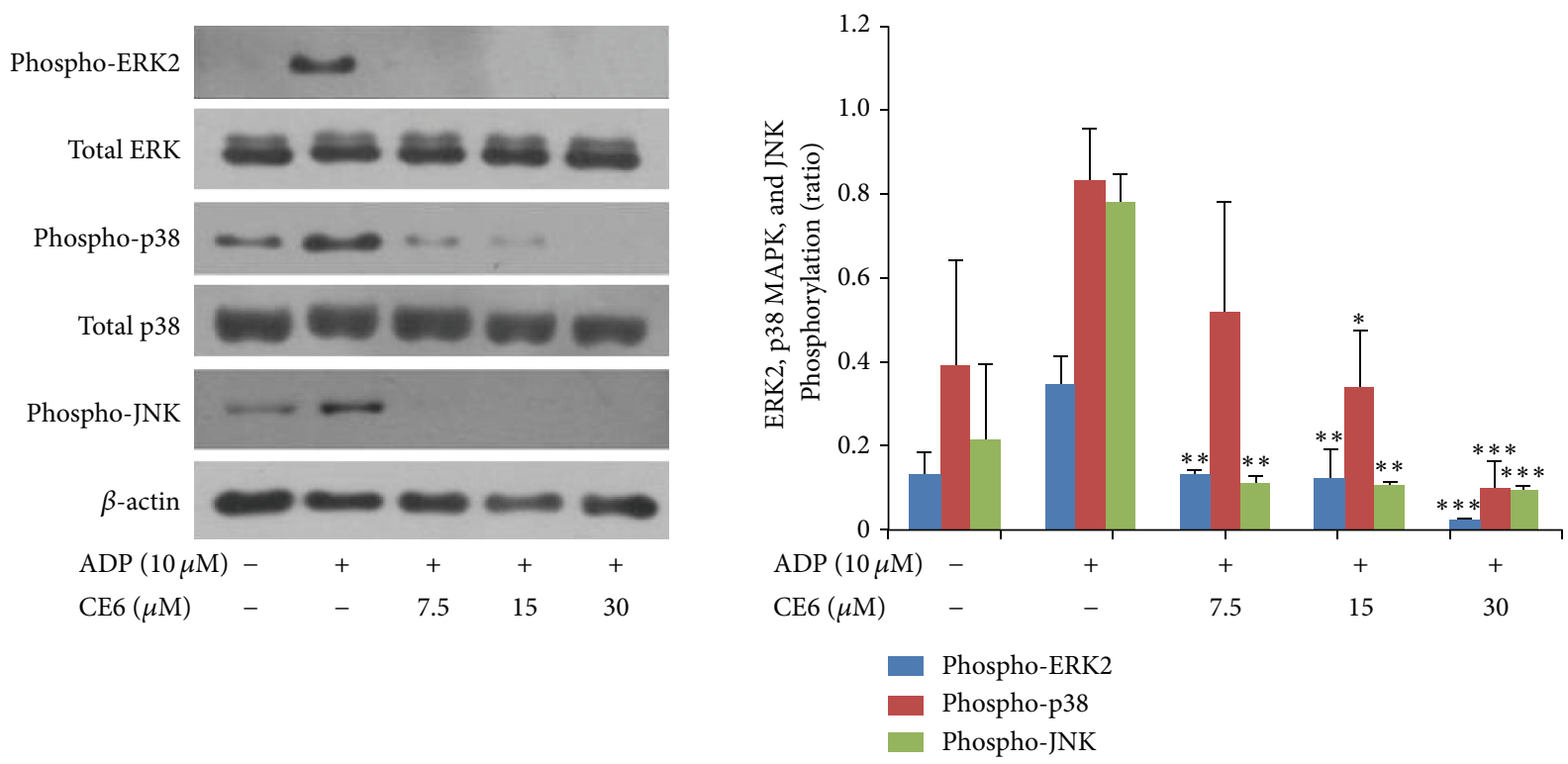

(a)
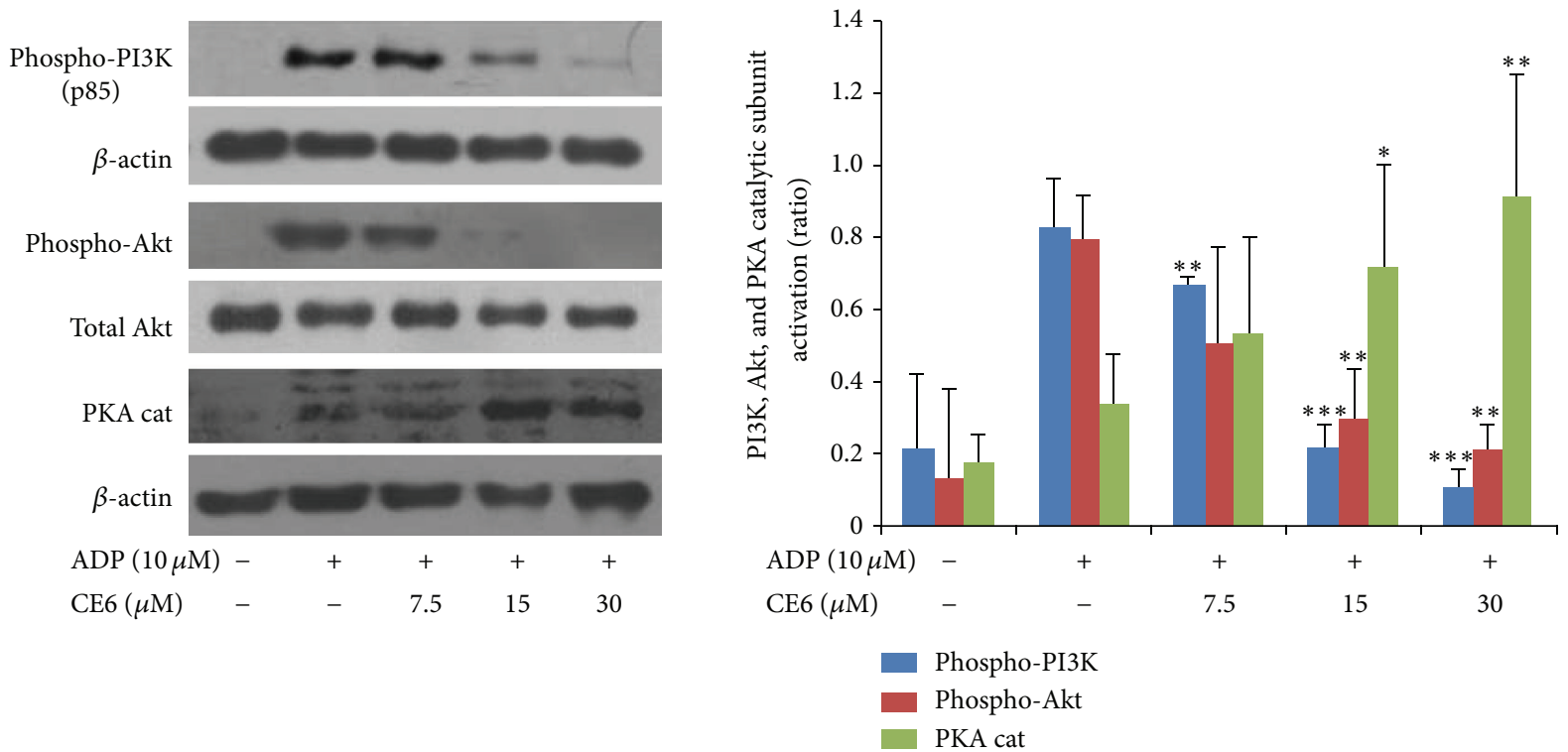

(b)

FIGURE 8: Effects of CE6 on ADP-induced phosphorylation of MAPKs, PI3K, and Akt and on expression of the PKA catalytic subunit. Washed platelets $\left(3 \times 10^{8} / \mathrm{mL}\right)$ were pre-incubated for 2 min with vehicle or CE6 at the indicated concentration. The platelets were then stimulated with $10 \mu \mathrm{M}$ ADP for $5 \mathrm{~min}$ at $37^{\circ} \mathrm{C}$. After terminating the reactions, total cell proteins were extracted. The proteins were separated by SDSPAGE and transferred onto nitrocellulose membranes. The membranes were then probed with antibodies against phospho-p44/42, p44/42, phospho-p38, p38, phospho-SAPK/JNK, and $\beta$-actin (a); and phospho-PI3K, phospho-Akt, Akt, PKA $\alpha / \beta / \gamma$ catalytic subunit, and $\beta$-actin (b). Antibody binding was visualized by chemiluminescence. All immunoblots are representative of three or four independent experiments.

the effects of CE6 on platelets, we further examined the phosphorylation of downstream signaling molecules including MAPKs, PI3K, and PKA. MAPKs include extracellular signal-related kinase 1/2 (ERK1/2 or p44/42), p38 MAPK, and JNK, which are all expressed in rat platelets. Our immunoblot analysis revealed that phosphorylation of all three MAPKs was almost completely blocked by pre-incubation with CE6 (Figure 8(a)).
It is well-established that PI3K plays crucial role in dense granule secretion along with signaling associated with secondary mediators such as ADP and TXA 2 [7]. In addition, PI3K and Akt are known to be phosphorylated by $\mathrm{G}_{\mathrm{i}}$-coupled receptor activation [4]. We therefore determined whether CE6 affected PI3K and Akt phosphorylation. Pre-incubation with CE6 significantly inhibited the phosphorylation of PI3K and Akt in rat platelets (Figure 8(b)). 


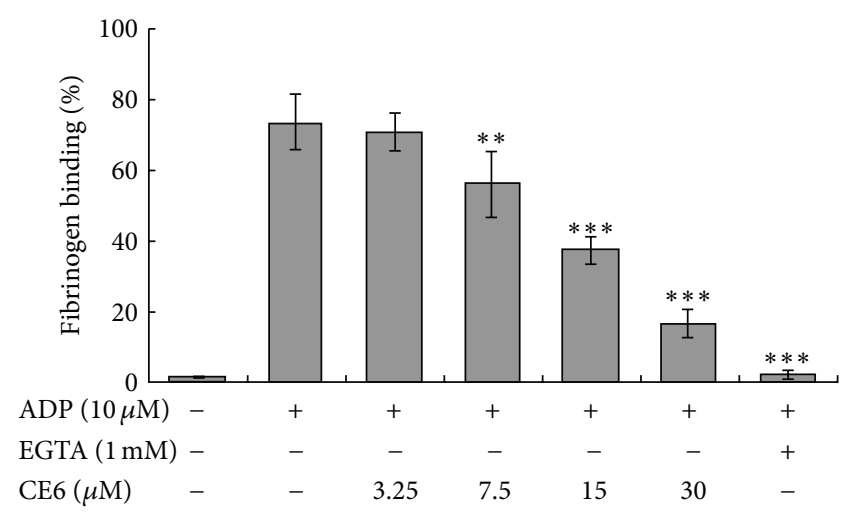

(a)

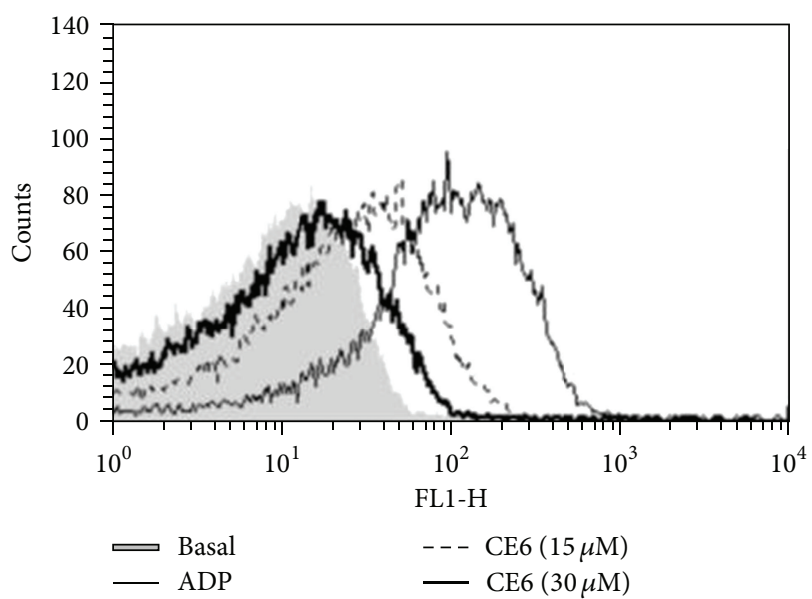

(b)

FIGURE 9: Effects of CE6 on fibrinogen binding to integrin $\alpha_{\text {IIb }} \beta_{3}$ in ADP-activated platelets. The inhibitory effects of CE6 on fibrinogen binding to integrin $\alpha_{\mathrm{IIb}} \beta_{3}$ in ADP-stimulated platelets were measured by flow cytometry (a). Washed platelets $\left(3 \times 10^{8} / \mathrm{mL}\right)$ were pretreated with vehicle (DMSO) or CE6 at concentrations ranging from $3.25 \mu \mathrm{M}$ to $30 \mu \mathrm{M}$. ADP $(10 \mu \mathrm{M})$ was then incubated with human fibrinogen labeled with Alexa Fluor $488(20 \mu \mathrm{g} / \mathrm{mL})$ for $5 \mathrm{~min}$. The cells were subsequently fixed with $0.5 \%$ paraformaldehyde at $4^{\circ} \mathrm{C}$ for $30 \mathrm{~min}$. Graphs showing fluorescent intensity present the data from one experiment but are representative of four independent trials. Data are expressed as the mean fluorescence intensity (MFI) of fibrinogen-positive platelets. Each graph presents the results expressed as percent of gated (A). ${ }^{* *} P<0.01$ and ${ }^{* * *} P<0.005$ compared to the agonist control.

Since pre-incubation with CE6 increased cAMP production in unstimulated platelets, we next explored whether PKA is activated by pretreatment with CE6. As shown in Figure 9(b), CE6 significantly enhanced expression of the PKA catalytic subunit.

3.9. CE6 Attenuates Fibrinogen Binding to Integrin $\alpha_{\mathrm{II}} \beta_{3}$. One consequence of ADP-induced platelet activation is a conformational change of integrin $\alpha_{\mathrm{IIb}} \beta_{3}$ [31] that binds to serum fibrinogen. Concomitant stimulation of two ADP receptors, $\mathrm{P} 2 \mathrm{Y}_{1}$ and $\mathrm{P} 2 \mathrm{Y}_{12}$, causes integrin $\alpha_{\mathrm{IIb}} \beta_{3}$ to assume an active conformation [32]. To determine whether CE6 affects the activation of $\alpha_{\mathrm{IIb}} \beta_{3}$, washed platelets were pre-incubated with different concentrations $(3.25 \sim 30 \mu \mathrm{M})$ of CE6 and incubated with fibrinogen bound to Alexa Fluor 488. Specific binding of the labeled fibrinogen was then measured. We found that CE6 inhibited fibrinogen binding in a concentration-dependent manner (Figures 9(a) and 9(b)).

\section{Discussion}

In the present study, we evaluated the inhibitory effects of CE6 on platelet aggregation and elucidated downstream pathways involved in the inhibition of ADP-induced platelet activation by CE6. ATP and serotonin secretion was inhibited by CE6. This compound also regulated $\left[\mathrm{Ca}^{2+}\right]_{i}$. Moreover, the phosphorylation of the three MAPKs, PI3K, and Akt was inhibited, and fibrinogen binding to integrin $\alpha_{\mathrm{II}} \beta_{3}$ was attenuated (Figure 10).

We demonstrated that CE6 prevented ADP-induced $\left[\mathrm{Ca}^{2+}\right]_{i}$ elevation in a concentration-dependent manner and significantly suppressed dense granule secretion. Upon ADP
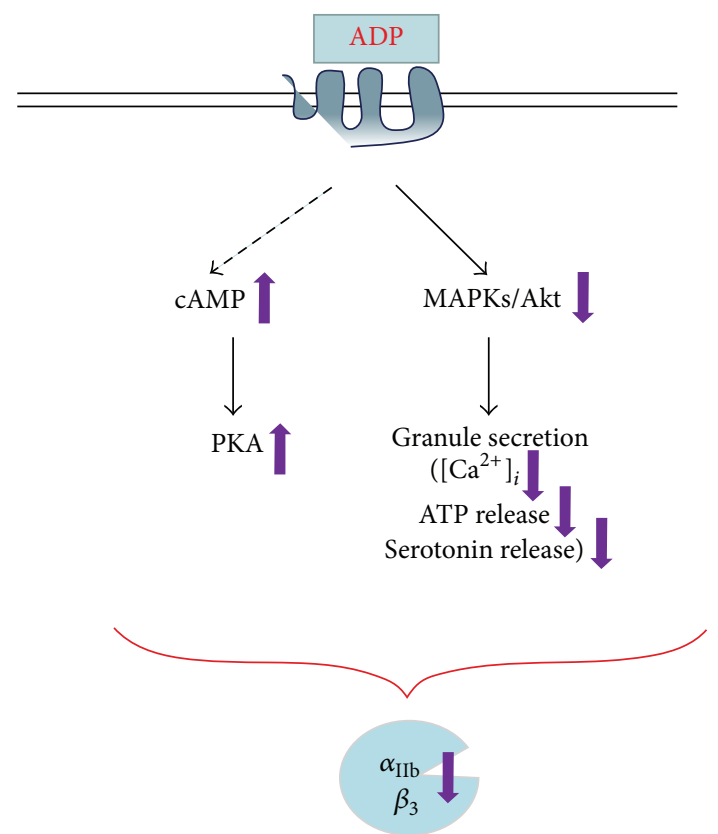

Activation by CE6

Inactivation by CE6

FIGURE 10: Schematic of CE6 antiplatelet activity and the underlying mechanism of action.

stimulation, a rapid rise in $\left[\mathrm{Ca}^{2+}\right]_{i}$ occurs due to PI3K activation [2]. Guidetti et al. also demonstrated that the inhibition of $\mathrm{P} 2 \mathrm{Y}_{12}$ (a $\mathrm{G}_{\mathrm{i}}$-coupled ADP receptor) completely 
prevents PKC activation and suppresses pleckstrin phosphorylation [2]. These findings suggest that CE6 inhibits calcium mobilization at least partially via the inhibition of DAG-PKC activity. Increased $\left[\mathrm{Ca}^{2+}\right]_{i}$ subsequently triggers platelet granule secretion (i.e., and dense granules) [33]. ATP released from dense granules causes a rapid influx of calcium by sensitizing the ionotropic receptor P2X1 [34]. On the other hand, $\mathrm{Ca}^{2+}$ chelation abolishes ATP release, indicating functional complementarities [35]. In addition, released granule contents (i.e., ATP and serotonin) help amplify platelet activation $[29,33,36]$. Taken together, our results along with data from the literature suggest that CE6 exerts broad inhibitory effects on granule secretion such as calcium, ATP, and serotonin, which mediated the antiplatelet activities of CE6.

$\mathrm{TXA}_{2}$ is an unstable aggregating factor, of which production was significantly inhibited by pre-incubation with CE6 in ADP-activated platelets. $\mathrm{TXA}_{2}$ is an important mediator generated by the initial activation of phospholipase $\mathrm{A}_{2}$. Recent studies have shown that activation of the $\mathrm{P} 2 \mathrm{Y}_{1}$ purinergic receptor $\left(G_{\mathrm{q}}\right.$-coupled ADP receptor) enhances $\mathrm{TXA}_{2}$ receptor (TP receptor) activation [37], and the TP receptor subsequently promotes ADP secretion [38]. These findings suggest that cross-activity exists between $G$ proteinmediated receptors. Given that the network between ADP and $\mathrm{TXA}_{2}$ enables the rapid formation of a haemostatic plug, the inhibition of $\mathrm{TXA}_{2}$ generation seems to play an important role in mediating the inhibitory effect of CE6 on ADP-induced activation. TXA 2 is produced by sequential activation of COX-1 and TXAS from arachidonic acid, a byproduct of phospholipid breakdown. As presented in Figure 6, CE6 markedly suppressed COX-1 activity but not that of TXAS (data not shown). This result suggests that the inhibition of $\mathrm{TXA}_{2}$ production (determined by measuring the $\mathrm{TXB}_{2}$ metabolite levels) by CE6 is likely due to decreased availability of $\mathrm{PGH}_{2}$, a substrate of TXAS.

Mammalian platelets express three MAPKs: ERK1/2, p38MAPK, and JNK. Previous studies showed that ERK has a crucial role in $\mathrm{TXA}_{2}$ generation [11, 19]. Moreover, ERK activation following GPIb stimulation leads to integrin $\alpha_{\mathrm{IIb}} \beta_{3}$ activation [19]. p38-MAPK and ERK are known to have important roles in granule secretion and $\mathrm{TXA}_{2}$ release, suggesting that the effects of these two factors are secondary to the effect on granule secretion [39]. Our results indicated that CE6 suppresses dense granule secretion, TXA formation, and $\alpha_{\mathrm{II}} \beta_{3}$ activation (at least in part) through inhibition of the ERK and p38-MAPK pathways. On the other hand, previous studies have presented and demonstrated that JNK-/- platelets are associated with increased bleeding time, decreased integrin $\alpha_{\mathrm{II}} \beta_{3}$ activation, and severe granule secretion impairment [40]. Therefore, it seems that the inhibition of JNK phosphorylation plays an important role in the platelet activation process.

The most noteworthy finding from the present study was that cAMP production was elevated by CE6 treatment in resting or ADP-activated platelets. $\mathrm{P}_{2} \mathrm{Y}_{12}$ receptor is capable of inhibiting AC, thereby promoting platelet aggregation [2]. Additionally, ADP suppresses intracellular cAMP levels increased by constitutive activation of $\mathrm{AC}$ in intact platelets [8]. Srinivasan et al. also reported that adenosine-based $\mathrm{P} \mathrm{Y}_{12}$ (coupled to $\mathrm{G}_{\mathrm{s}}$ ) antagonists inhibit platelet aggregation, but adenosine-based $\mathrm{P}_{2} \mathrm{Y}_{1}$ (coupled to $\mathrm{G}_{\mathrm{q}}$ ) antagonists do not [8]. As such, considerable evidence has accumulated supporting the theory that cAMP has a broad inhibitory effect on platelet activation [24, 41]. With this knowledge, we tested our hypothesis that CE6 would raise cAMP levels in the rat platelets. As expected, CE6 markedly elevated cAMP concentrations compared to forskolin, suggesting that the inhibitory effect of CE6 on platelet activation is mediated by cAMP. Moreover, the synergistic effect we observed with the AC activator but not the PDE inhibitor indicates that the elevation of cAMP production by CE6 is not due to the inhibition of cAMP degradation through PDE activity suppression.

It is well known that the target of cAMP is PKA, which is composed of a regulatory subunit dimer and two catalytic subunits $[1,6]$. Indeed, treatment with CE6 at concentrations that inhibited platelet aggregation increased the expression of the active PKA catalytic subunit in the present study. Our finding indicated that activation of the cAMP-PKA pathway is responsible for the inhibition of platelet aggregation by CE6. Unexpectedly, fibrinogen binding to integrin $\alpha_{\mathrm{IIb}} \beta_{3}$ was much more affected by CE6 treatment compared to intracellular cAMP levels. Several previous studies have reported that inhibition of AC or ADP receptors does not induce platelet aggregation $[32,42]$. Thus, the cAMP pathway elicited by CE6 might be of potentiating effect rather than direct effect on integrin signaling.

The inhibition of integrin activation is of great interest for the development of antiplatelet drugs. As a consequence of active integrin conformation, outside-in signaling is a major driving force for complete platelet aggregation [43]. Reversible cell aggregation is eventually undergoing stabilization, followed by outside-in signaling of fibrinogen. Several lines of research have demonstrated that platelet aggregates are completely or partially disassembled in ADP- or collagenstimulated platelets through either blocking of the $\mathrm{P}_{2} \mathrm{Y}_{12}$ receptor or suppression of PI3K $[8,44]$. Based on these findings and our data, we propose that ADP-activated PI3K plays an important role in integrin activation, likely via $\mathrm{G}_{i}{ }^{-}$ coupled signaling.

Alternatively, it was previously shown that PKC activation is inhibited by either blocking the $\mathrm{P}_{2} \mathrm{Y}_{12}$ receptor or inhibiting PI3K activity [45]. These findings suggest that PKC holds a pivotal role in the PI3K-Akt signaling pathway. As discussed previously, the inhibition of PKC activity likely influenced the negative effects of CE6 on platelet activation. During the late stage of integrin activation, the ADP-P2 $\mathrm{Y}_{12}$ receptor helps regulate thrombus stabilization through the activation of PI3K and Akt, which inhibits cAMP production [44]. Kim et al. also reported that cAMP downregulates the activity of Akt in COS cell by interfering PtdIns-3,4,5- $\mathrm{P}_{3}$ formation [46], demonstrating the essential role of ADP in activation of the Akt pathway [4]. Results from our study suggest that the suppression of fibrinogen binding to $\alpha_{\mathrm{II}} \beta_{3}$ by CE6 is mediated by decreased activation of PI3K and Akt. 


\section{Conclusion}

As summarized in Figure 10, we demonstrated that CE6 inhibited ADP-induced platelet aggregation, increases of $\left[\mathrm{Ca}^{2+}\right]_{i}, \mathrm{TXA}_{2}$ production, and dense granule secretion (i.e., ATP and serotonin release) in a concentration-dependent manner. The phosphorylation of the three MAPKs (ERK1/2, p38-MAPK, and JNK) was also markedly inhibited by CE6 treatment. While the PI3K-Akt pathway was suppressed by CE6, the cAMP-PKA pathway was activated. Based on our data, we propose that CE6 acts through the CAMP-PKA pathway to attenuate the expression and activity of intracellular signaling molecules and suppress the activation of integrin $\alpha_{\text {IIb }} \beta_{3}$ activated by PI3K-Akt signaling, thereby preventing the aggregation of ADP-stimulated platelets. The development of innovative antiplatelet drugs has been focused on the inhibition of ADP and $\mathrm{TXA}_{2}$ signaling [37]. Thus, CE6 could be developed as a therapeutic agent for preventing thrombosis and ischemia.

\author{
Abbreviations \\ CE6: Chlorin e6 \\ MAPK: Mitogen-activated protein kinase \\ $\mathrm{TXA}_{2}$ : Thromboxane $\mathrm{A}_{2}$ \\ PI3K: Phosphatidylinositol 3-kinase \\ GPCR: G-protein coupled receptor \\ DAG: Diacylglycerol \\ PKA: Protein kinase A \\ PKC: $\quad$ Protein kinase C.
}

\section{Conflict of Interests}

The authors declare that they have no conflict of interests and have no commercial interest in the product described in this paper.

\section{Authors' Contribution}

Ji Young Park and Hyun Dong Ji equally contributed to this work.

\section{Acknowledgment}

This work was supported by a Grant (110109-03-3-HD110) from the Ministry of Food, Agriculture, Forestry and Fisheries, Republic of Korea.

\section{References}

[1] S. Gambaryan, A. Kobsar, N. Rukoyatkina et al., "Thrombin and collagen induce a feedback inhibitory signaling pathway in platelets involving dissociation of the catalytic subunit of protein kinase a from an NFאB-I $\kappa$ B complex," The Journal of Biological Chemistry, vol. 285, no. 24, pp. 18352-18363, 2010.

[2] G. F. Guidetti, P. Lova, B. Bernardi et al., "The Gi-coupled P2Y12 receptor regulates diacylglycerol-mediated signaling in human platelets," The Journal of Biological Chemistry, vol. 283, no. 43, pp. 28795-28805, 2008.
[3] A. Moers, N. Wettschureck, S. Grüner, B. Nieswandt, and S. Offermanns, "Unresponsiveness of platelets lacking both $\mathrm{G} \alpha \mathrm{q}$ and $\mathrm{G} \alpha 13$. Implications for collagen-induced platelet activation," The Journal of Biological Chemistry, vol. 279, no. 44, pp. 45354-45359, 2004.

[4] S. Kim, J. Jin, and S. P. Kunapuli, "Akt activation in platelets depends on Gi signaling pathways," The Journal of Biological Chemistry, vol. 279, no. 6, pp. 4186-4195, 2004.

[5] M. Grenegård, K. Vretenbrant-Öberg, M. Nylander et al., "The ATP-gated P2X1 receptor plays a pivotal role in activation of aspirin-treated platelets by thrombin and epinephrine," The Journal of Biological Chemistry, vol. 283, no. 27, pp. 18493-18504, 2008.

[6] A.-A. Weber, T. Hohlfeld, and K. Schrör, "cAMP is an important messenger for ADP-induced platelet aggregation," Platelets, vol. 10, no. 4, pp. 238-241, 1999.

[7] A. Stojanovic, J. A. Marjanovic, V. M. Brovkovych et al., "A phosphoinositide 3-kinase-AKT-nitric oxide-cGMP signaling pathway in stimulating platelet secretion and aggregation," The Journal of Biological Chemistry, vol. 281, no. 24, pp. 16333-16339, 2006.

[8] S. Srinivasan, F. Mir, J.-S. Huang, F. T. Khasawneh, S. C.-T. Lam, and G. C. le Breton, "The P2Y12 antagonists, 2methylthioadenosine $5^{\prime}$-monophosphate triethylammonium salt and cangrelor (ARC69931MX), can inhibit human platelet aggregation through a Gi-independent increase in cAMP levels," The Journal of Biological Chemistry, vol. 284, no. 24, pp. 16108-16117, 2009.

[9] L. Stefanini, R. C. Roden, and W. Bergmeier, "CalDAG-GEFI is at the nexus of calcium-dependent platelet activation," Blood, vol. 114, no. 12, pp. 2506-2514, 2009.

[10] M. Antl, M.-L. von Brühl, C. Eiglsperger et al., "IRAG mediates $\mathrm{NO} / \mathrm{cGMP}$-dependent inhibition of platelet aggregation and thrombus formation," Blood, vol. 109, no. 2, pp. 552-559, 2007.

[11] D. Yacoub, J.-F. Théorêt, L. Villeneuve et al., "Essential role of protein kinase $\mathrm{C} \delta$ in platelet signaling, $\alpha \mathrm{IIb} \beta 3$ activation, and thromboxane A2 release," The Journal of Biological Chemistry, vol. 281, no. 40, pp. 30024-30035, 2006.

[12] G. Davì and C. Patrono, "Mechanisms of disease: platelet activation and atherothrombosis," The New England Journal of Medicine, vol. 357, no. 24, pp. 2482-2494, 2007.

[13] F. Y. Ali, S. J.. Davidson, L. A. Moraes et al., "Role of nuclear receptor signaling in platelets: antithrombotic effects of PPAR 3," FASEB Journal, vol. 20, no. 2, pp. 326-328, 2006.

[14] J. M. Gibbins, "Platelet adhesion signalling and the regulation of thrombus formation," Journal of Cell Science, vol. 117, part 16, pp. 3415-3425, 2004.

[15] A. M. Pancioli and T. G. Brott, "Therapeutic potential of platelet glycoprotein IIb/IIIa receptor antagonists in acute ischaemic stroke: scientific rationale and available evidence," CNS Drugs, vol. 18, no. 14, pp. 981-988, 2004.

[16] Y.-H. Moon, S.-M. Kwon, H.-J. Kim et al., "Efficient preparation of highly pure chlorin e6 and its photodynamic anti-cancer activity in a rat tumor model," Oncology Reports, vol. 22, no. 5, pp. 1085-1091, 2009.

[17] N. D. Namsa, H. Tag, M. Mandal, P. Kalita, and A. K. Das, "An ethnobotanical study of traditional anti-inflammatory plants used by the Lohit community of Arunachal Pradesh, India," Journal of Ethnopharmacology, vol. 125, no. 2, pp. 234-245, 2009.

[18] A. J. Sarac and A. Gur, "Complementary and alternative medical therapies in fibromyalgia," Current Pharmaceutical Design, vol. 12, no. 1, pp. 47-57, 2006. 
[19] P. Huang, C. Xu, J. Lin et al., "Folic acid-conjugated graphene oxide loaded with photosensitizers for targeting photodynamic therapy," Theranostics, vol. 1, pp. 240-250, 2011.

[20] H. Guo, X. Pan, R. Mao et al., "Alkylated porphyrins have broad antiviral activity against hepadnaviruses, flaviviruses, filoviruses, and arenaviruses," Antimicrobial Agents and Chemotherapy, vol. 55, no. 2, pp. 478-486, 2011.

[21] K. S. McMahon, T. J. Wieman, P. H. Moore, and V. H. Fingar, "Effects of photodynamic therapy using mono-L-aspartyl chlorin e6 on vessel constriction, vessel leakage, and tumor response," Cancer Research, vol. 54, no. 20, pp. 5374-5379, 1994.

[22] A. B. Samal, T. E. Zorina, and S. N. Cherenkevich, "Chlorine e6sensitized photoinhibition of thrombocyte aggregation. Participation of active oxygen forms," Gematologiya $i$ Transfusiologiya, vol. 36, no. 4, pp. 19-21, 1991.

[23] D.-H. Lee, H.-J. Cho, H.-Y. Kang, M. H. Rhee, and H.-J. Park, "Total saponin from Korean red ginseng inhibits thromboxane A2 production associated microsomal enzyme activity in platelets," Journal of Ginseng Research, vol. 36, no. 1, pp. 40-46, 2012.

[24] J. Y. Park, W. J. Oh, M. J. Kim et al., "Mechanism of anti-platelet activity of Oligoporus tephroleucus oligoporin A: involvement of extracellular signal-regulated kinase phosphorylation and cyclic nucleotide elevation," Platelets, vol. 23, no. 5, pp. 376-385, 2012.

[25] H.-S. Lee, S. D. Kim, W. M. Lee et al., "A noble function of BAY 11-7082: inhibition of platelet aggregation mediated by an elevated CAMP-induced VASP, and decreased ERK2/JNK1 phosphorylations," European Journal of Pharmacology, vol. 627, no. 1-3, pp. 85-91, 2010.

[26] J. Schaeffer and M. P. Blaustein, "Platelet free calcium concentrations measured with fura- 2 are influenced by the transmembrane sodium gradient," Cell Calcium, vol. 10, no. 2, pp. 101-113, 1989.

[27] J. Schlossmann, A. Ammendola, K. Ashman et al., "Regulation of intracellular calcium by a signalling complex of IRAG, IP3 receptor and cGMP kinase I $\beta$,' Nature, vol. 404, no. 6774, pp. 197-201, 2000.

[28] Q. Ren, C. Wimmer, M. C. Chicka et al., "Munc13-4 is a limiting factor in the pathway required for platelet granule release and hemostasis," Blood, vol. 116, no. 6, pp. 869-877, 2010.

[29] D. Viisoreanu and A. Gear, "Effect of physiologic shear stresses and calcium on agonist-induced platelet aggregation, secretion, and thromboxane A2 formation," Thrombosis Research, vol. 120, no. 6, pp. 885-892, 2007.

[30] L. Navarro-Núñez, J. Rivera, J. A. Guerrero, C. Martínez, V. Vicente, and M. L. Lozano, "Differential effects of quercetin, apigenin and genistein on signalling pathways of proteaseactivated receptors PAR1 and PAR4 in platelets," British Journal of Pharmacology, vol. 158, no. 6, pp. 1548-1556, 2009.

[31] B. Nieswandt, V. Schulte, A. Zywietz, M.-P. Gratacap, and S. Offermanns, "Costimulation of Gi- and G12/G13-mediated signaling pathways induces integrin $\alpha \mathrm{IIb} \beta 3$ activation in platelets," The Journal of Biological Chemistry, vol. 277, no. 42, pp. 3949339498, 2002.

[32] H.-M. Jantzen, D. S. Milstone, L. Gousset, P. B. Conley, and R. M. Mortensen, "Impaired activation of murine platelets lacking Gai2," The Journal of Clinical Investigation, vol. 108, no. 3, pp. 477-483, 2001.

[33] R. Flaumenhaft, "Molecular basis of platelet granule secretion," Arteriosclerosis, Thrombosis, and Vascular Biology, vol. 23, no. 7, pp. 1152-1160, 2003.
[34] M. P. Mahaut-Smith, S. J. Ennion, M. G. Rolf, and R. J. Evans, "ADP is not an agonist at P2X1 receptors: evidence for separate receptors stimulated by ATP and ADP on human platelets," British Journal of Pharmacology, vol. 131, no. 1, pp. 108-114, 2000.

[35] C. Oury, E. Toth-Zsamboki, J. Vermylen, and M. F. Hoylaerts, "P2X1-mediated activation of extracellular signal-regulated kinase 2 contributes to platelet secretion and aggregation induced by collagen," Blood, vol. 100, no. 7, pp. 2499-2505, 2002.

[36] A. Garcia, H. Shankar, S. Murugappan, S. Kim, and S. P. Kunapuli, "Regulation and functional consequences of ADP receptor-mediated ERK2 activation in platelets," Biochemical Journal, vol. 404, no. 2, pp. 299-308, 2007.

[37] R. F. Storey, H. M. Judge, R. G. Wilcox, and S. Heptinstall, "Inhibition of ADP-induced P-selectin expression and plateletleukocyte conjugate formation by clopidogrel and the P2Y12 receptor antagonist AR-C69931MX but not aspirin," Journal of Thrombosis and Haemostasis, vol. 88, no. 3, pp. 488-494, 2002.

[38] J. F. Barton, A. R. Hardy, A. W. Poole, and S. J. Mundell, "Reciprocal regulation of platelet responses to $\mathrm{P} 2 \mathrm{Y}$ and thromboxane receptor activation," Journal of Thrombosis and Haemostasis, vol. 6, no. 3, pp. 534-543, 2008.

[39] P. Flevaris, Z. Li, G. Zhang, Y. Zheng, J. Liu, and X. Du, "Two distinct roles of mitogen-activated protein kinases in platelets and a novel Racl-MAPK-dependent integrin outsidein retractile signaling pathway," Blood, vol. 113, no. 4, pp. 893901, 2009.

[40] F. Adam, A. Kauskot, P. Nurden et al., "Platelet JNK1 is involved in secretion and thrombus formation," Blood, vol. 115, no. 20, pp. 4083-4092, 2010.

[41] A. Garcia, T. M. Quinton, R. T. Dorsam, and S. P. Kunapuli, "Src family kinase-mediated and Erk-mediated thromboxane A2 generation are essential for VWF/GPIb-induced fibrinogen receptor activation in human platelets," Blood, vol. 106, no. 10, pp. 3410-3414, 2005.

[42] J. L. Daniel, C. Dangelmaier, J. Jin, Y. B. Kim, and S. P. Kunapuli, "Role of intracellular signaling events in ADP-induced platelet aggregation," Thrombosis and Haemostasis, vol. 82, no. 4, pp. 1322-1326, 1999.

[43] D. R. Phillips, K. S. S. Prasad, J. Manganello, M. Bao, and L. Nannizzi-Alaimo, "Integrin tyrosine phosphorylation in platelet signaling," Current Opinion in Cell Biology, vol. 13, no. 5, pp. 546-554, 2001.

[44] J. M. E. M. Cosemans, I. C. A. Munnix, R. Wetzker, R. Heller, S. P. Jackson, and J. W. M. Heemskerk, "Continuous signaling via PI3K isoforms $\beta$ and $\gamma$ is required for platelet $\mathrm{ADP}$ receptor function in dynamic thrombus stabilization," Blood, vol. 108, no. 9, pp. 3045-3052, 2006.

[45] C.-C. Wu, S.-Y. Wu, C.-Y. Liao, C.-M. Teng, Y.-C. Wu, and S.-C. Kuo, "The roles and mechanisms of PAR4 and P2Y12/phosphatidylinositol 3-kinase pathway in maintaining thrombin-induced platelet aggregation," British Journal of Pharmacology, vol. 161, no. 3, pp. 643-658, 2010.

[46] S. Kim, K. Jee, D. Kim, H. Koh, and J. Chung, "Cyclic AMP inhibits akt activity by blocking the membrane localization of PDK1," The Journal of Biological Chemistry, vol. 276, no. 16, pp. 12864-12870, 2001. 


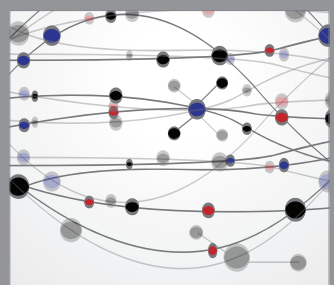

The Scientific World Journal
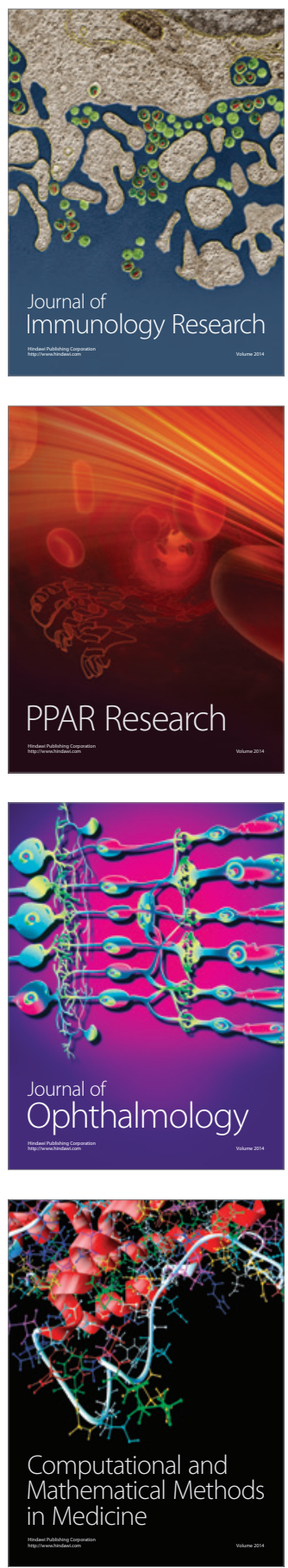

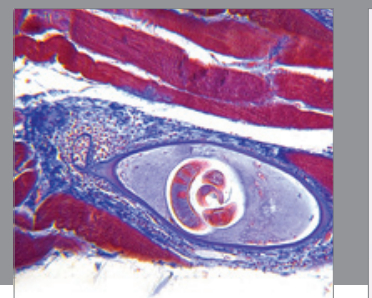

Gastroenterology

Research and Practice
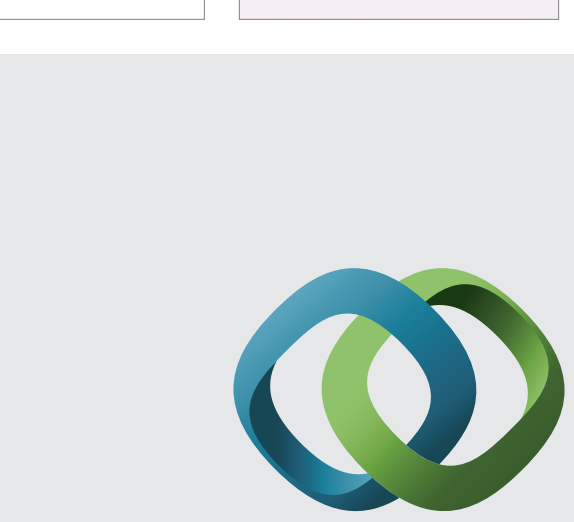

\section{Hindawi}

Submit your manuscripts at

http://www.hindawi.com
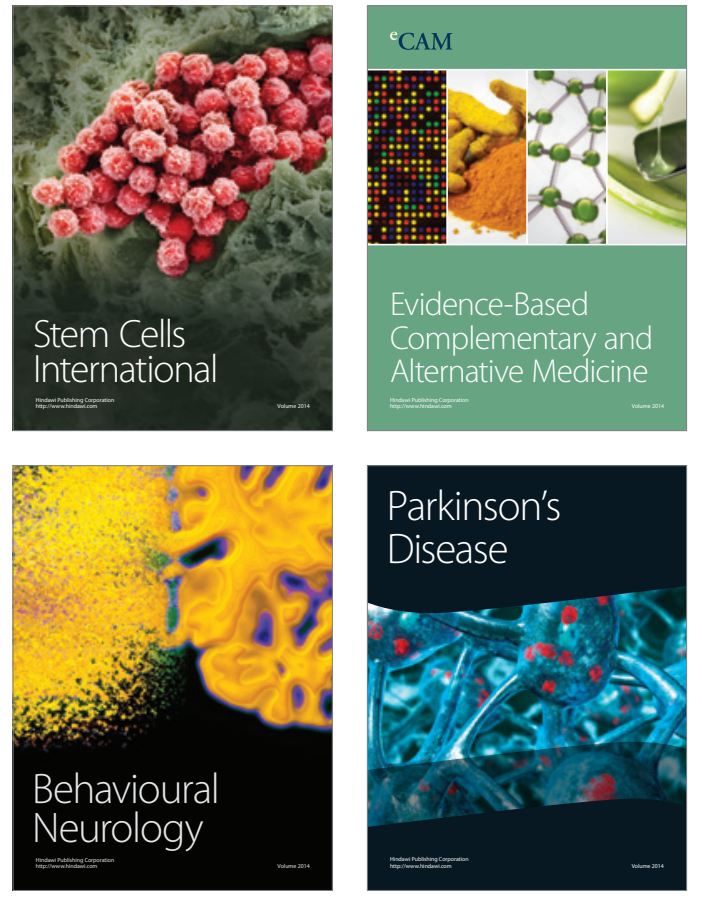
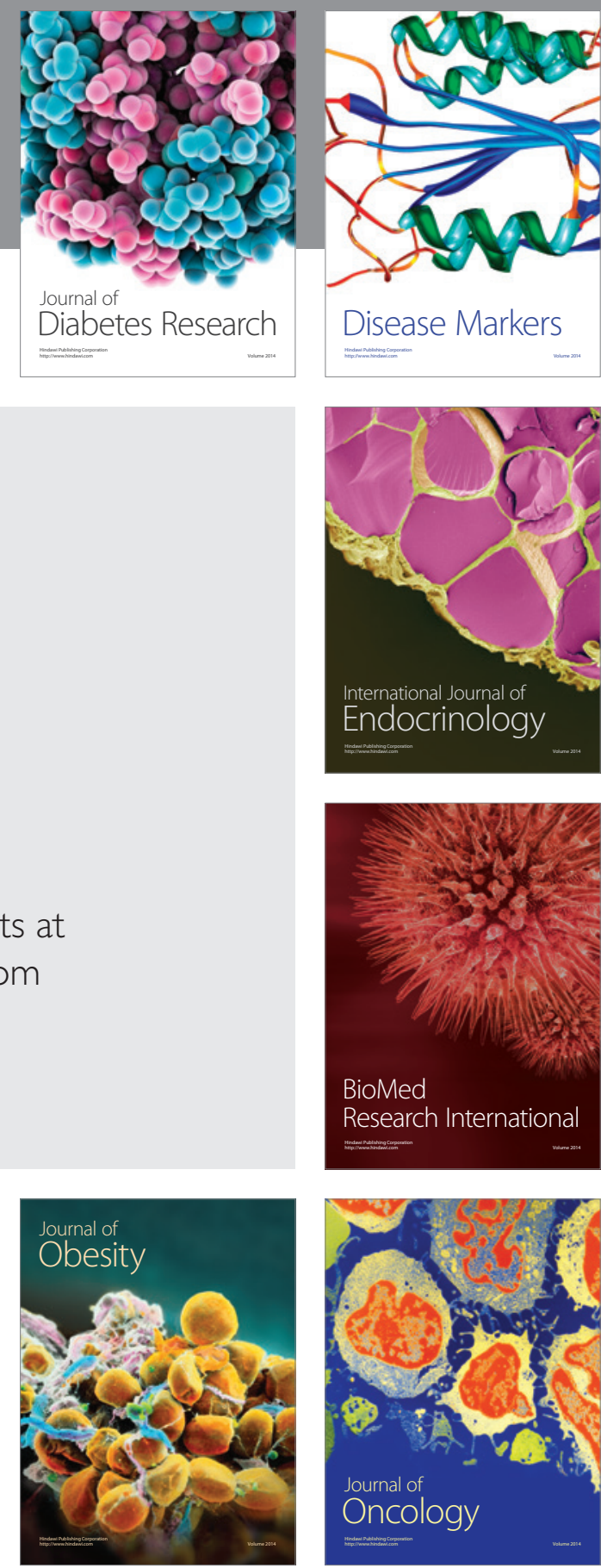

Disease Markers
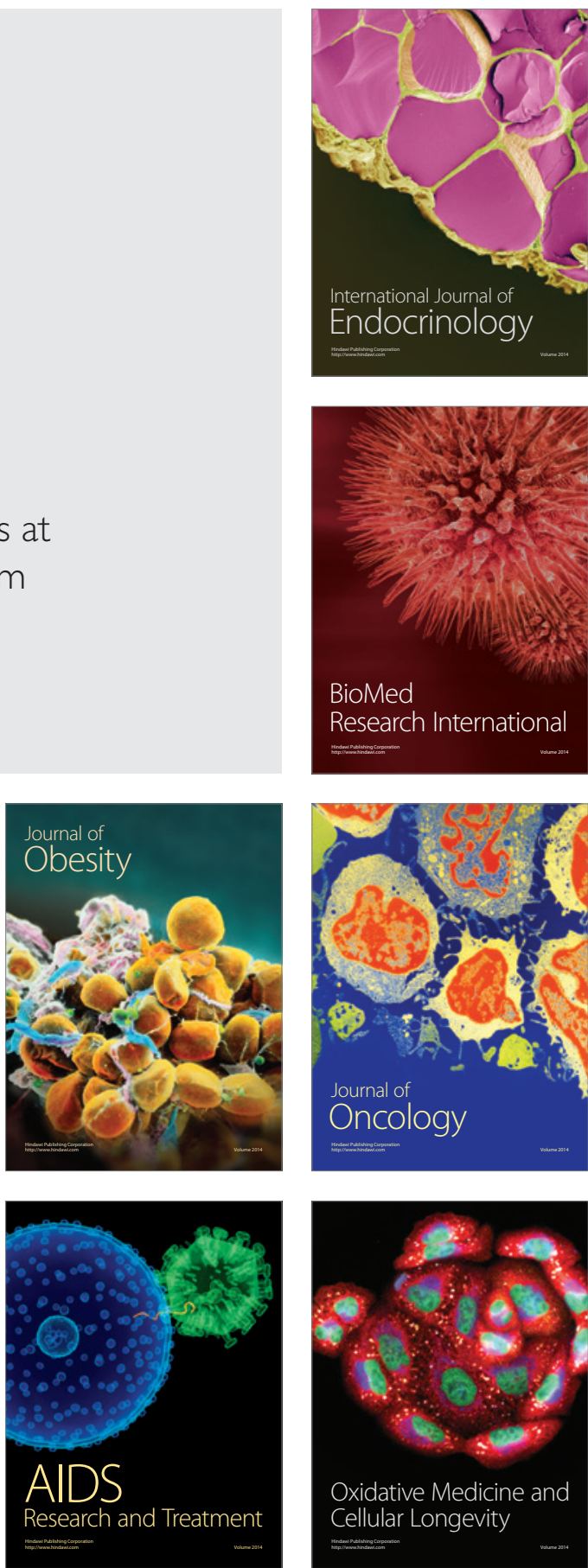